\title{
Development verification of coatings made from porous ceramic-matrix composite materials
}

\author{
Sergey Reznik ${ }^{1, *}$, Pavel Prosuntsov ${ }^{1}$, and Konstantin Mikhaylovskiy ${ }^{1}$ \\ ${ }^{1}$ Bauman Moscow State Technical University, 105005, 5/1, 2-nd Baumanskaya str., Moscow, Russia
}

\begin{abstract}
The paper presents methodology and results of tests conducted for porous carbon ceramic specimens on a high-temperature gas dynamic facility to simulate real operating conditions for heat shields. The structure of the materials before and after tests is compared.
\end{abstract}

\section{Introduction}

Ablative heat-shield materials are traditionally used to protect the load-bearing structure of re-entry space vehicles. At present, PICA is considered to be the best heat shield material. PICA, which stands for Phenolic Impregnated Carbon Ablator, is composed of a porous carbon base and phenol-formaldehyde resin. However, studies conducted at NASA Langley research center [1] show that the use of carbon materials such as ACC-6, together with high porosity thermal insulation, makes it possible to create more weight-efficient designs. Ceramic matrix composites (CMC) reinforced with carbon fiber, despite their high oxidation-resistance and erosion-resistance and good mechanical characteristics, possess high density and thermal conductivity, which reduces their attraction as heat-shield materials. The most perspective direction in heat shield development is associated with porous CCM $[2,3]$ that combine the effective density in the range $1200-1800 \mathrm{~kg} / \mathrm{m}^{3}$ and a substantially lower thermal conductivity coefficient $[4,5]$. However, to date there is no experimental evidence that porous CCM can withstand the high-enthalpy air flux.

\section{Test objects}

The test objects were samples of porous ceramic matrix composite materials with the apparent density $1200-1800 \mathrm{~kg} / \mathrm{m}^{3}$, reinforced with ceramic fibers. The samples' microstructure was investigated using the PhenomProX optical microscope. The images of CMC with the $1200 \mathrm{~kg} / \mathrm{m}^{3}$ apparent density (Fig. 1a) clearly show carbon fibers $20 \mu \mathrm{m}$ in diameter, covered with a 1 micron crust of silicon carbide. There are pores, 60 to $100 \mu \mathrm{m}$ size, between the fibers. The images of the material with $1400 \mathrm{~kg} / \mathrm{m}^{3}$ density (Fig. 1b) clearly show fiber microstructure with 2 to $3 \mu \mathrm{m}$ silicon carbide crust. The characteristic pore size between the fibers, compared to the $1200 \mathrm{~kg} / \mathrm{m}^{3}$ sample, decreased and became 50 to $70 \mu \mathrm{m}$. A sample of $1600 \mathrm{~kg} / \mathrm{m}^{3}$ material (Fig. 1c), compared to less dense samples,

\footnotetext{
* Corresponding author: sreznik@bmstu.ru
} 
looks much more monolithic with individual local pores. With the same diameter carbon fibers, the thickness of the silicon carbide crust increased up to $4 \mu \mathrm{m}$. The pores are smaller, in the range of 30 to $40 \mu \mathrm{m}$. A sample of $1800 \mathrm{~kg} / \mathrm{m}^{3}$ material (Fig. 1d) looks almost monolithic. Individual fibers are almost indistinguishable. The thickness of the silicon carbide crust increased up to 8 microns. The characteristic pore size in the sample does not exceed $20 \mu \mathrm{m}$.

\section{Test equipment}

The CCM samples were tested at the high-temperature gas dynamic test facility with a high-frequency ВГУ-4 (VGU-4) plasmatron at the Ishlinsky Institute for Problems in Mechanics of the Russian Academy of Sciences (Moscow) (Fig. 2) [6-8]. The VGU-4 plasmatron in the standard subsonic mode enables the pressure range in the test chamber from $600 \mathrm{~Pa}$ to atmospheric pressure and the enthalpy range from 10 to $40 \mathrm{MJ}$ on the jet axis.

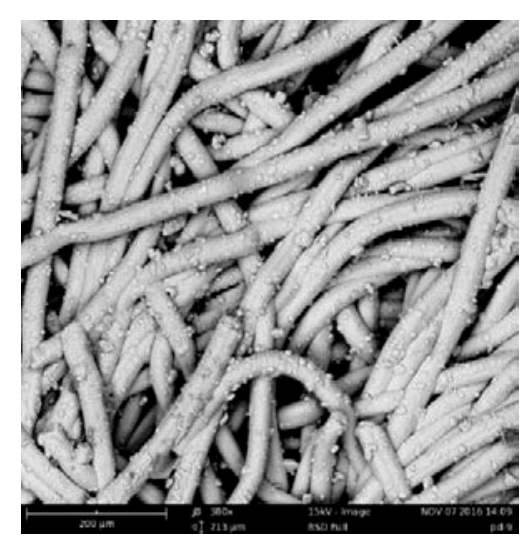

a

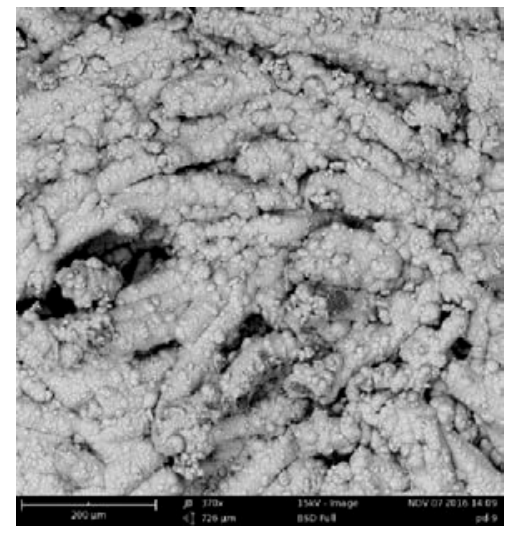

$\mathrm{c}$

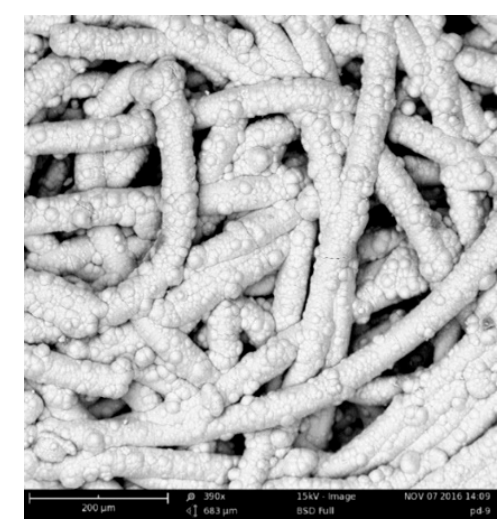

b

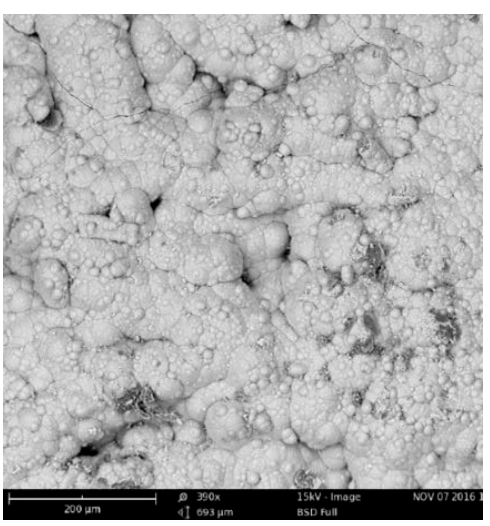

$\mathrm{d}$

Fig. 1. CCM surface microstructure KMKM (380x magnification optical microscope): a - apparent density $1200 \mathrm{~kg} / \mathrm{m}^{3} ; \mathrm{b}-1400 \mathrm{~kg} / \mathrm{m}^{3} ; \mathrm{c}-1600 \mathrm{~kg} / \mathrm{m}^{3} ; \mathrm{d}-1800 \mathrm{~kg} / \mathrm{m}^{3}$ 


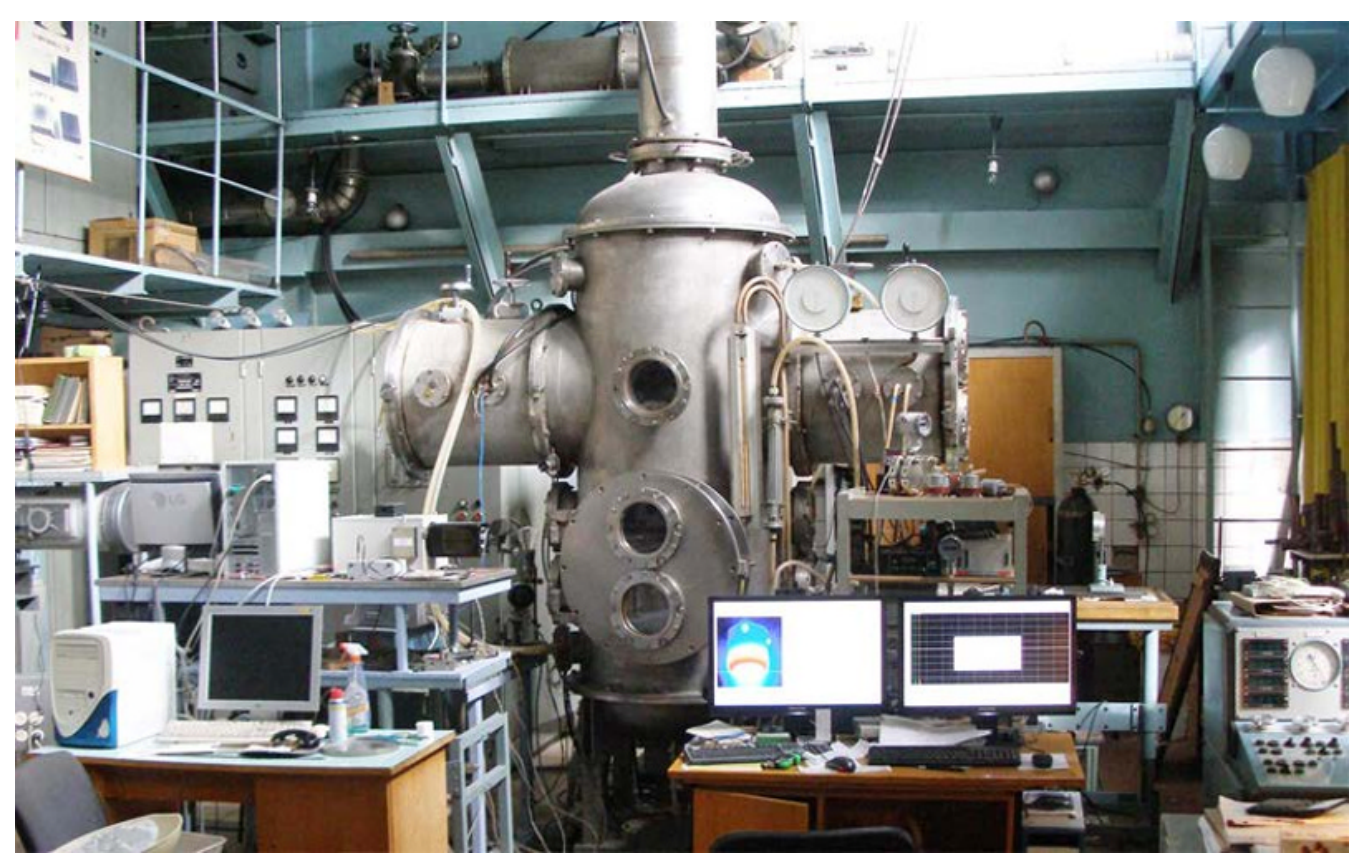

Fig. 2. High-temperature gas dynamic test facility with VGU-4 high-frequency plasmatron

\section{Test methods}

Thermal tests were conducted using test coupons: circular plates with $26.5 \mathrm{~mm}$ front face diameter, a conical side surface with $30^{\circ}$ divergence half-angle and $4.0 \mathrm{~mm}$ thickness. The coupons were heated incrementally up to $1720^{\circ} \mathrm{C}$ and subsequent held at this temperature. The temperature of the frontal surface of the samples was measured using the "Tandem VS$415 \mathrm{U}^{\prime \prime}$ thermometer calibrated according to the model of an absolutely black body in the $700^{\circ}$ to $2300^{\circ} \mathrm{C}$ temperature range.

Fig. 3 shows a typical thermal image of the investigated CCM sample surface. In the course of the experiment, the display showed the maximum surface temperature and the temperature distribution as functions of time. The maximum temperature was specified for a rectangle selected on the surface and the temperature distribution was taken along the scanning line in Fig. 3. Fig. 4 shows the main parameters of the plasmatron operation and the surface temperature as functions of time. The surface temperature was measured by a spectral -ratio pyrometer and a thermal camera. 


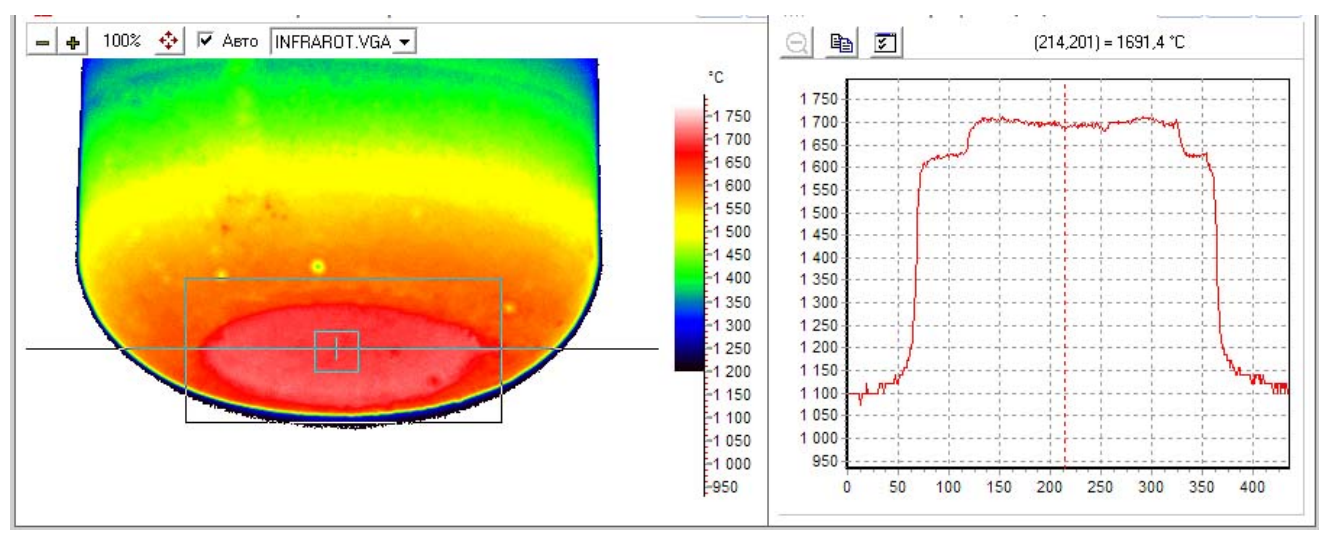

Fig. 3. Coupon thermal image and areas where the maximum temperature was measured

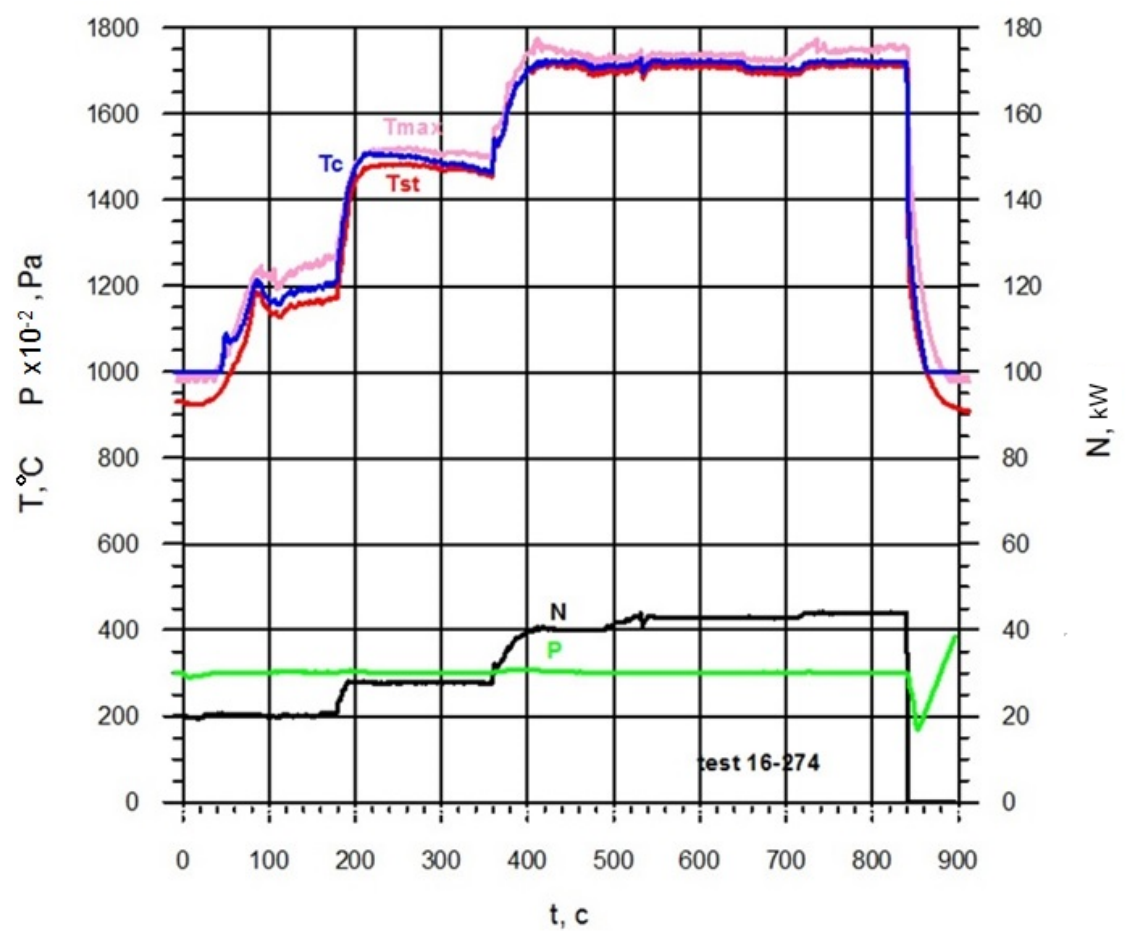

Fig. 4. Plasmatron operating parameters and surface temperature as functions of time; measurement by a spectral-ratio pyrometer and a thermal camera: $T$ - temperature, ${ }^{\circ} \mathrm{C} ; N-$ energy, $\mathrm{kW} ; P-$ pressure, $\mathrm{GPa}$

\section{Test results}

To illustrate test results, let us consider a CCM sample with $1600 \mathrm{~kg} / \mathrm{m}^{3}$ apparent density. The test coupon was incrementally heated for $360 \mathrm{~s}$ up to $1720^{\circ} \mathrm{C}$ and was held at this temperature for $420 \mathrm{~s}$. The total mass ablation was $0.8091 \mathrm{~g}(19.2 \%)$, with zero linear ablation. The surface remained uniform, without any visible fiber ablation areas (Fig. 5). The front surface was coated with a silicon dioxide crust found to be intact (Fig. 6). Fibers' 
shapes were visible beneath the crust, and single fibers ablated. This CCM sample has passed the tests successfully. No failure occurred, even though in the last two minutes local failure origins were observed in the form of rapid (a few seconds long) formation and disappearance of the local overheating zones, which is typical of silicon carbide materials and coatings.

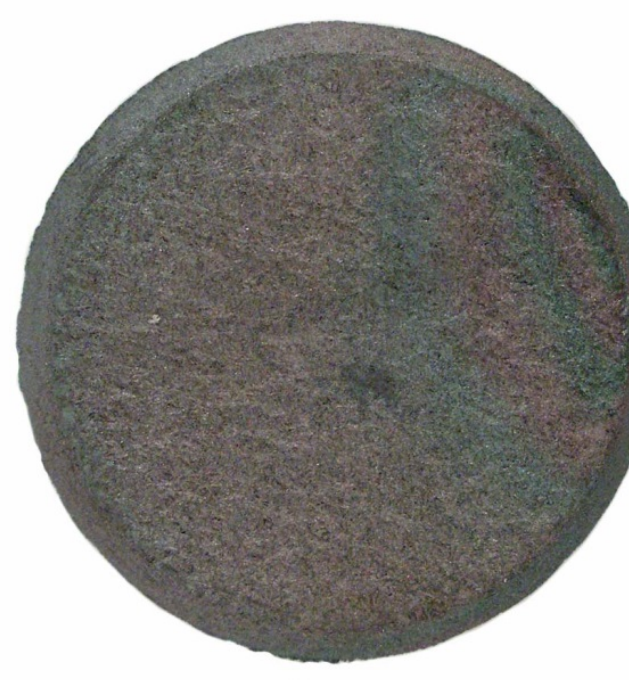

a

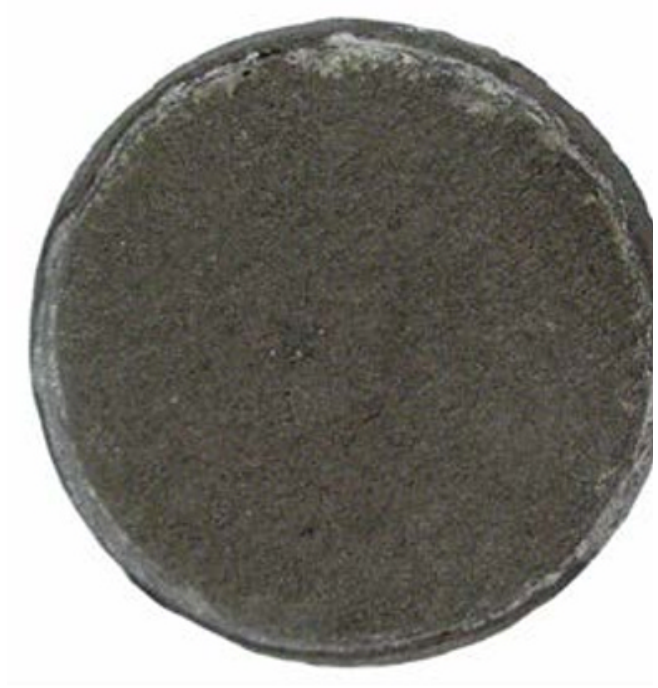

b

Fig. 5. Front surface of the test coupon with $1600 \mathrm{~kg} / \mathrm{m}^{3}$ apparent density: $\mathrm{a}$ - before test; $\mathrm{b}$ - after test

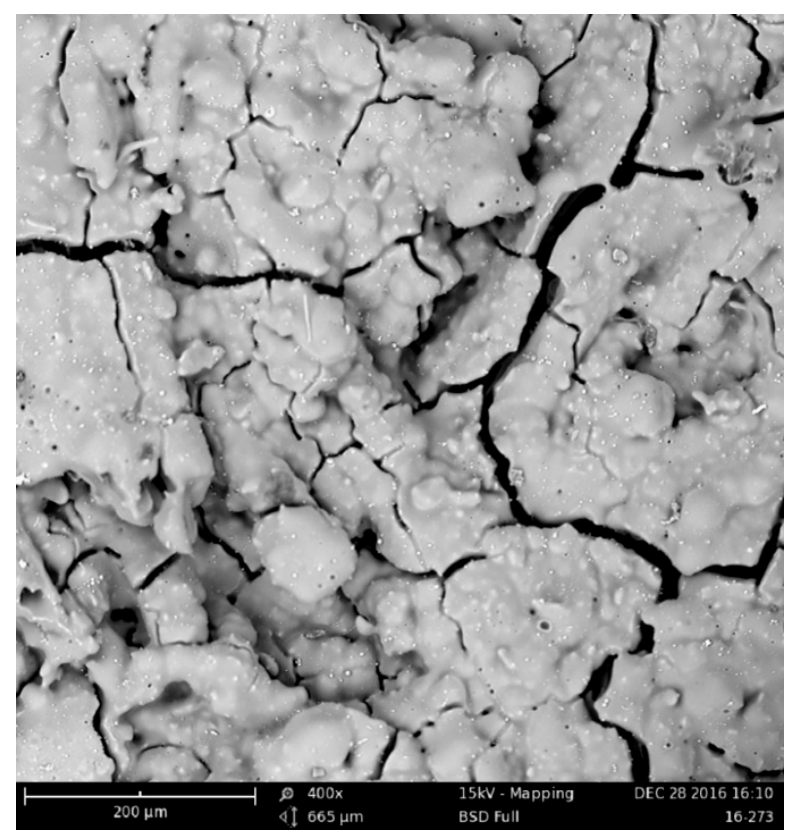

Fig. 6. Surface of the $1600 \mathrm{~kg} / \mathrm{m}^{3}$ after thermochemical resistance tests (magnification $400 \mathrm{x}$ ) 


\section{Conclusion}

The tests of porous CCM samples conducted on the VGU-4 plasmatron demonstrated that this class materials with $1600 \mathrm{~kg} / \mathrm{m}^{3}$ apparent density can successfully withstand highenthalpy air flux and, consequently, is suitable for reusable heat shields.

The authors would like to express their gratitude to their colleagues A.F. Kolesnikov, A.N. Gordeev, N.Y. Taraskin, I.R. Shafikova for their indispensable cooperation.

\section{References}

1. S.P. Walker, K. Daryabeigi, J.A. Samareh, S.C. Armand, S.V. Perino, 55th AIAA/ASME/ASCE/AHS/ASC Structures, Structural Dynamics, and Materials Conf. (2014). 10.2514/6.2014-0350.

2. P.V. Prosuntsov, A.V. Shulyakovskii, N.Y. Taraskin, J. Eng. Phys. and Thermophys. 90, 1 (2017)

3. S.V. Reznik, P.V. Prosuntsov, K.V. Mikhailovskii, J. Eng. Phys. and Thermophys. 88, 3 (2015).

4. P.V. Prosuntsov, N.Y. Taraskin, Matec Web of Conf. 01092. (2016). DOI: 10.1051/matecconf/20167201092.

5. P.V. Prosuntsov, N.Y. Taraskin, Matec Web of Conf. 01008. (2017). DOI: 10.1051/matecconf/20179201008.

6. A.N. Gordeev A.F. Kolesnikov, Phys.-Chem. Kinetics in Gas Dyn. 7. (2008). www.chemphys.edu.ru/pdf/2008-09-01-020.pdf

7. A.F. Kolesnikov, A.N. Gordeev, V.I. Saharov, Phys.-Chem. Kinetics in Gas Dyn. 7. (2008). www.chemphys.edu.ru/pdf/2008-09-01-003.pdf

8. V.V. Gorskij, A.N. Gordeev, A.A. Dmitrieva, A.F. Kolesnikov, Phys.-Chem. Kinetics in Gas Dyn. 18, 2 (2017). 12 p. http://chemphys.edu.ru/issues/2017-18-2/articles/736/ 